\title{
Adrenal Venous Sampling in Primary Hyperaldosteronism
}

\author{
Abbey L. Fingeret · James A. Lee
}

Published online: 11 December 2013

(C) Springer Science + Business Media New York 2013

\begin{abstract}
Adrenal venous sampling (AVS) is used to distinguish unilateral from bilateral aldosterone hypersecretion as a cause of primary hyperaldosteronism (PHA). This distinction is critical because unilateral disease is treated, and often cured, by adrenalectomy, whereas bilateral hypersecretion should be managed medically. In this article, we review the epidemiology and etiologies of PHA, present screening guidelines for hypertensive patients with suspected PHA, assess the utility and pitfalls of crosssectional imaging, and discuss the indications for and interpretation of AVS.
\end{abstract}

Keywords Primary hyperaldosteronism $\cdot$ Aldosteroneproducing adenoma - Idiopathic hyperaldosteronism . Adrenal vein sampling - Adrenal venous sampling . Screening · Diagnostic imaging · Selectivity index · Laterality index

\section{Introduction}

Primary hyperaldosteronism (PHA) is a treatable, and possibly curable, etiology of secondary hypertension. The most common causes of PHA include aldosterone-producing adenoma (APA) and bilateral adrenal hyperplasia or idiopathic hyperaldosteronism (IHA). Less common causes of PHA include adrenocortical carcinoma, unilateral

This article is part of the Topical Collection on Minimally Invasive Endocrine Surgery.

A. L. Fingeret $(\bowtie) \cdot J$. A. Lee

Section of Endocrine Surgery, New York-Presbyterian Hospital of Columbia University Medical Center, 177 Fort Washington Avenue, MHB 7-GS 313, New York, NY 10032, USA

e-mail: af2451@columbia.edu hyperplasia, familial hyperaldosteronism, and ectopic aldosterone-secreting tumors.

APA, first described by Conn [1] in 1956, accounts for 30-35\% of cases of PHA, and IHA represents the majority of the remaining cases. Compared to IHA, patients with an APA generally have higher aldosterone secretion rates often manifested by more severe hypertension and hypokalemia [2, 3]. Although historical studies suggest a prevalence of PHA of $<1 \%$ among hypertensive patients, more recent studies note a prevalence of 5-13\% among all hypertensive patients [4-6, 7••, 8-15].

Precise determination of the etiology of hyperaldosteronism is necessary to guide operative intervention for APA or medical therapy for IHA. The ultimate treatment goal for either strategy is to prevent the morbidity and mortality from longstanding hypertension including renal insufficiency and cardiovascular pathology [10, 16-18]. Surgery for unilateral pathology corrects hyperaldosteronism and hypokalemia and improves blood pressure control in nearly all patients, with 35-60\% requiring no further antihypertensive agents [19-24]. The aldosteronoma resolution score (ARS) was developed to stratify the likelihood of normotension following adrenalectomy for APA. This scoring system accounts for the number of antihypertensives at the time of adrenalectomy (two points for two or fewer medications) and important clinical factors (one point for each favorable clinical feature: body mass index of $\leq 25 \mathrm{~kg} / \mathrm{m}^{2}$, duration of hypertension of $<6$ years, and female gender). A score of 1 or less predicts a $27 \%$ likelihood of resolution, while a score greater than 3 predicts resolution in $75 \%$ of cases [25].

\section{Clinical Presentation}

PHA should be suspected in patients with hypertension, unexplained hypokalemia, and metabolic alkalosis [17]. 
Despite this classic description, less than half of patients with PHA are hypokalemic at the time of presentation, and hypokalemia is seen in $<20 \%$ of patients with bilateral hyperplasia $[4,15,26]$. Occasionally patients with PHA may present with hypokalemia and normal blood pressure [27].

\section{Screening}

Because APA can be a reversible cause of hypertension, screening for APA is recommended in hypertensive patients with hypokalemia, severe or resistant hypertension, and/or an adrenal incidentaloma [28]. More specific criteria for screening of hypertensive patients were developed by the Endocrine Society: hypertension and hypokalemia (either spontaneous or on low-dose diuretic therapy); severe hypertension (defined as systolic blood pressure $>160 \mathrm{mmHg} /$ diastolic blood pressure $>100 \mathrm{mmHg}$, or hypertension refractory to three or more pharmacologic agents); patients with an incidental finding of an adrenal mass; patients with a family history of early onset hypertension or cerebral vascular accident under age 40 years; all patients with a first degree relative with PHA [7••].

Initial evaluation of this selected population includes an early morning, ambulatory biochemical assay of plasma aldosterone concentration (PAC) and plasma renin activity (PRA) or plasma renin concentration (PRC). For accurate interpretation of these studies, mineralocorticoid receptor antagonists such as spironolactone and eplerenone should be suspended for 6 weeks prior to testing. In normal subjects, the PRA is $<1 \mathrm{ng} / \mathrm{ml}$, and the PRC is undetectable. In patients with $\mathrm{PHA}$, the PAC is generally elevated to $>15 \mathrm{ng} / \mathrm{dl}$, but the PAC/ PRA ratio is a more sensitive indicator. A PAC/PRA ratio of $>20$ is suggestive of PHA, while some clinicians advocate utilizing a cutoff of 30 for greater specificity [29, 30]. One study of 434 hypertensive patients found that utilizing criteria of both a PAC $>20 \mathrm{ng} / \mathrm{dl}$ and PAC/PRA ratio of $>30 \mathrm{dem}-$ onstrated a $90 \%$ sensitivity and $91 \%$ specificity for PHA [31].

\section{Diagnostic Imaging}

Once the diagnosis of PHA has been confirmed with biochemical testing, diagnostic imaging should be obtained as the first modality to differentiate APA from IHA and localize the lesion(s). Computed tomography (CT) is the recommended primary imaging modality [7••, 32]. CT may identify a unilateral lesion, bilateral lesions, bilateral hyperplasia, or less frequently unilateral hyperplasia. Patients with hyperplasia may also have normal-appearing adrenal glands [4]. Magnetic resonance imaging (MRI) may replace CT as the primary imaging modality for patients with a contraindication to ionizing radiation.

Despite technological advances and improved spatial resolution of cross-sectional imaging, CT and MRI are limited diagnostic modalities for HPA since they provide only anatomic and not functional information. The presence or absence of adrenal lesions on cross-sectional imaging can demonstrate a significant amount of discordance with a functional test such as adrenal venous sampling (AVS). Retrospective reviews demonstrate that $\mathrm{CT}$ is accurate in only 50-53\% of patients and if utilized as the sole lateralization study would have incorrectly excluded $22 \%$ from adrenalectomy and lead to unnecessary adrenalectomy in $25 \%$ [33-35]. Another retrospective study of 71 patients found a sensitivity of $87 \%$ with a specificity of $71 \%$ for the diagnosis of APA on CT alone [36]. A systematic review of 950 patients across 38 studies found CT and MRI to be discordant with AVS localization in $37.8 \%$ of patients, and, if operative intervention had been based on imaging alone, would have led to inappropriate adrenalectomy in $18.5 \%$ and inappropriate medical management in $19.1 \%$ of cases [37••]. Additionally, the absence of a mass on CT does not exclude APA; even with thin helical collimation, CT may miss lesions $<3 \mathrm{~mm}$ in diameter [38, 39].

\section{Indications for AVS}

AVS was introduced in the 1960s to differentiate unilateral from bilateral aldosterone hypersecretion [40]. AVS remained the primary diagnostic modality for 2 decades until cross-sectional imaging with $\mathrm{CT}$ and MRI became more widely available [41]. Additionally, CT and/or MRI can aid in operative planning for patients who will eventually require adrenalectomy following confirmatory lateralization by AVS.

Given the limitations of CT and MRI in PHA, the Endocrine Society recommends AVS in all patients with biochemical laboratory findings of PHA who are candidates for adrenalectomy to determine whether the etiology is bilateral or unilateral [7••]. Most clinicians recommend selective AVS for all patients over the age of 40 . Patients under the age of 40 with a solitary unilateral lesion greater than one centimeter by CT or MRI do not necessarily require AVS [4, 42]. This selective approach is justified by the increasing incidence of adrenal hyperplasia with age. Others recommend selective AVS based on the biochemical characteristics of good-risk operative candidates - a serum potassium level of $<3.5 \mathrm{mmol} / \mathrm{l}$ or an estimated glomerular filtration rate of $>100 \mathrm{ml} / \mathrm{min}$ with at least an 8-mm low-attenuation adrenal mass by CT was $53 \%$ sensitive and $100 \%$ specific for an APA [43].

Adrenal Venous Sampling

\section{Procedure}

There is not a standardized approach to AVS for HPA; however, certain requirements must be met to ensure an 
accurate interpretation of the results. The inferior vena cava (IVC) and bilateral adrenal veins are accessed percutaneously via the common femoral vein by the specialist. The adrenal veins may be cannulated for specimen collection either simultaneously or sequentially [44, 45]. Sequential adrenal venous cannulation is more common, being used by more than half of performing centers with similar success as the more technically challenging simultaneous access technique [44, 46•].

Aldosterone and cortisol levels are measured in both adrenal veins and the IVC, which serves as a baseline comparator. The specimens are assayed with serial dilution from $1: 1$ to $1: 10$ and $1: 50$ [2, 33, 47, 48]. Although early technical guides to the procedure recommended duplicate collection of all samples, more recent data demonstrate no benefit to duplicate specimens but longer procedure time and higher cost [49].

In experienced hands, AVS is a low-risk procedure with a complication rate of $<2.5 \%$. The most common complication is a hematoma at the femoral venous access site, occurring in $2 \%$ of patients undergoing AVS. Fortunately, adrenal vein dissection, adrenal rupture, and adrenal hemorrhage are rare events $[33,35,47,50,51]$.

\section{Synthetic Adrenocorticotropic Hormone (ACTH) Stimulation}

The purposes of ACTH stimulation during AVS are to minimize the stress-induced fluctuations in aldosterone secretion due to sequentially cannulated adrenal veins, to maximize the gradient in cortisol from the adrenal vein to the IVC for confirmation of successful cannulation, and to maximize aldosterone secretion from an APA [33]. Some studies suggest that synthetic ACTH stimulation does not increase the diagnostic accuracy of AVS [50, 52, 53], while others recommend either a bolus dose or continuous infusion for improved technical success, selectivity, and lateralization rates $[45,51,54,55]$. One recent retrospective review of 220 AVS procedures found an increase in technical success from 44 to $82 \%$ with the addition of ACTH stimulation [56]. A study comparing bolus dose ACTH to continuous infusion found no difference in success rate by infusion strategy [57•].

\section{Selectivity Index (SI)}

The SI measures the adequacy of the cannulation of the adrenal veins and is the ratio between cortisol levels in the respective adrenal vein and in the IVC. Because of the small size of the adrenal veins, blood sampled at the time of AVS is often obtained near the orifice of the vein and may be diluted. This dilution as well as difficulty cannulating the vein introduce error in the measurement of adrenal vein aldosterone levels, which most often occurs in the case of the right adrenal vein. The simultaneous measurement of cortisol concentrations allows for correction of this dilution by providing a normalizing factor. The success of cannulation determined by SI differs for non-stimulated and ACTH-stimulated AVS samples: without stimulation, an SI of greater than three confirms cannulation (though some centers report an SI as low as 1.1), and with ACTHstimulation, an SI of more than five is considered adequate $[47,51,58,59 \cdot 0]$. Some clinicians advocate the addition of catecholamine sampling for confirmation of both selectivity and laterality, but this method is not commonly used and requires further validation [60-62].

Successful biochemical assay generally depends upon the ability to selectively cannulate the right adrenal vein, which is technically more challenging than the left adrenal vein due to its small length and near perpendicular take-off from the IVC. Experienced interventionalists obtain right adrenal venous cannulation in $81-96 \%$ of patients [33, $37 \bullet \bullet, 38,63]$. Lower volume centers or less experienced clinicians may have lower success rates of $40-80 \%$ [11, $50,64]$. Intraprocedural measurement of cortisol to determine SI can significantly increase the success rate of AVS to $85-90 \%$, especially in lower volume centers, but requires up to $30 \mathrm{~min}$ of additional procedure time [65-68]. CT venography or cone beam CT during AVS is an additional adjunct that can improve right adrenal vein cannulation to up to $98 \%$, but is not widely available $[54,69-$ 71]. A systematic, multidisciplinary approach to the collection and interpretation of adrenal venous samples also improves yield [72].

\section{Laterality Index}

Once successful cannulation has been confirmed, localization of aldosterone hypersecretion via the laterality index is calculated by comparing the aldosterone-to-cortisol ratio between the left and right adrenal veins. It is important to use the aldosterone-to-cortisol ratio in order to control for dilutional effects, particularly of the inferior phrenic vein into the left adrenal vein. When comparing the aldosteroneto-cortisol ratios of the dominant to non-dominant side, a threshold value of four is the most commonly used criteria to determine hypersecretion from one gland [46•, 59••, 66], though some studies report criteria as low as two and up to five as a cutoff value [4, 33, 50, 73]. Using a laterality index of four as the threshold for APA yields a sensitivity of $81-98 \%$ and a specificity of $94-100 \%$ [33, 50, 52, 59••, 64, 74-78].

Additional confirmatory biochemical assays may be useful adjuncts to the laterality index. Contralateral suppression of aldosterone secretion may be evident in the setting of an APA (i.e., the nondominant adrenal vein 
aldosterone-to-cortisol ratio may be less than the IVC aldosterone-to-cortisol ratio). This non-dominant aldosterone suppression can be used to confirm contralateral APA in $93 \%$ of cases [33]. Recently, the measurement of 18-oxocortisol levels in adrenal vein samples has shown promise in localizing APA, but requires further study [79].

\section{Conclusions}

AVS is used to distinguish unilateral from bilateral aldosterone hypersecretion as a cause of PHA. Patients treated with adrenalectomy for APA or unilateral aldosterone hypersecretion have significantly improved hypokalemia and blood pressure levels. Following biochemical confirmation of PHA by a PAC/PRA ratio of $>20$, lateralization should proceed with cross-sectional imaging by CT. Select good-risk surgical candidates under 40 years of age with a unilateral adenoma of low attenuation by CT may proceed directly to adrenalectomy. However, all others should undergo AVS with ACTH stimulation for a functional evaluation of lateralization. Cannulation success rates may be increased with intraprocedural cortisol assays or CT guidance. With the use of ACTH stimulation, a selectivity index of three to five should be used to confirm adrenal vein cannulation, while a laterality index of 4 or greater is indicative of unilateral disease. Results should ideally be interpreted by a multidisciplinary team.

Compliance with Ethics Guidelines Conflict of Interest Abbey L. Fingeret and James A. Lee declare that they have no conflict of interest.

Human and Animal Rights and Informed Consent This article does not contain any studies with human or animal subjects performed by any of the authors.

\section{References}

Papers of particular interest, published recently, have been highlighted as:

- Of importance

•- Of major importance

1. Conn JW. Aldosterone in clinical medicine; past, present, and future. AMA Arch Intern Med. 1956;97(2):135-44.

2. Young WF. Primary aldosteronism: renaissance of a syndrome. Clin Endocrinol (Oxf). 2007;66(5):607-18.

3. Wu VC, Chueh SC, Chang HW, Lin WC, Liu KL, Li HY, et al. Bilateral aldosterone-producing adenomas: differentiation from bilateral adrenal hyperplasia. QJM. 2008;101(1):13-22.

4. Mulatero P, Stowasser M, Loh KC, Fardella CE, Gordon RD, Mosso L, et al. Increased diagnosis of primary aldosteronism, including surgically correctable forms, in centers from five continents. J Clin Endocrinol Metab. 2004;89(3):1045-50.
5. Douma S, Petidis K, Doumas M, Papaefthimiou P, Triantafyllou A, Kartali N, et al. Prevalence of primary hyperaldosteronism in resistant hypertension: a retrospective observational study. Lancet. 2008;371(9628):1921-6.

6. Hannemann A, Bidlingmaier M, Friedrich N, Manolopoulou J, Spyroglou A, Volzke H, et al. Screening for primary aldosteronism in hypertensive subjects: results from two German epidemiological studies. Eur J Endocrinol. 2012;167(1):7-15.

7. - Funder JW, Carey RM, Fardella C, Gomez-Sanchez CE, Mantero F, Stowasser M, et al. Case detection, diagnosis, and treatment of patients with primary aldosteronism: an endocrine society clinical practice guideline. J Clin Endocrinol Metab. 2008;93(9):3266-81. Clinical practice guidelines developed by committee consensus panel of The Endocrine Society using systematic review of available published evidence including description of quality of evidence and strength of recommendations. Recommendations include screening for primary hyperaldosteronism with biochemical evaluation in higher risk groups of hypertensive patients, utilization of confirmatory testing, imaging with computed tomography, and universal performance of adrenal venous sampling by an experienced interventionalist for lateralization in surgical candidates, with laparoscopic adrenalectomy for unilateral source.

8. Steichen O, Zinzindohoue F, Plouin PF, Amar L. Outcomes of adrenalectomy in patients with unilateral primary aldosteronism: a review. Horm Metab Res. 2012;44(3):221-7.

9. Born-Frontsberg E, Reincke M, Rump LC, Hahner S, Diederich $\mathrm{S}$, Lorenz R, et al. Cardiovascular and cerebrovascular comorbidities of hypokalemic and normokalemic primary aldosteronism: results of the German Conn's Registry. J Clin Endocrinol Metab. 2009;94(4):1125-30.

10. Young WF Jr. Adrenal causes of hypertension: pheochromocytoma and primary aldosteronism. Rev Endocr Metab Disord. 2007;8(4):309-20.

11. Vonend O, Ockenfels N, Gao X, Allolio B, Lang K, Mai K, et al. Adrenal venous sampling: evaluation of the German Conn's registry. Hypertension. 2011;57(5):990-5.

12. Rossi GP, Seccia TM, Pessina AC. Primary aldosteronism. Part I: prevalence, screening, and selection of cases for adrenal vein sampling. J Nephrol. 2008;21(4):447-54.

13. Mosso L, Carvajal C, Gonzalez A, Barraza A, Avila F, Montero J, et al. Primary aldosteronism and hypertensive disease. Hypertension. 2003;42(2):161-5.

14. Fardella CE, Mosso L, Gomez-Sanchez C, Cortes P, Soto J, Gomez L, et al. Primary hyperaldosteronism in essential hypertensives: prevalence, biochemical profile, and molecular biology. J Clin Endocrinol Metab. 2000;85(5):1863-7.

15. Rossi GP, Bernini G, Caliumi C, Desideri G, Fabris B, Ferri C, et al. A prospective study of the prevalence of primary aldosteronism in 1,125 hypertensive patients. J Am Coll Cardiol. 2006;48(11):2293-300.

16. Milliez P, Girerd X, Plouin PF, Blacher J, Safar ME, Mourad JJ. Evidence for an increased rate of cardiovascular events in patients with primary aldosteronism. J Am Coll Cardiol. 2005;45(8):1243-8.

17. Mattsson C, Young WF Jr. Primary aldosteronism: diagnostic and treatment strategies. Nat Clin Pract Nephrol. 2006;2(4):198-208 quiz, $1 \mathrm{p}$ following 30 .

18. Omura M, Sasano H, Saito J, Yamaguchi K, Kakuta Y, Nishikawa T. Clinical characteristics of aldosterone-producing microadenoma, macroadenoma, and idiopathic hyperaldosteronism in 93 patients with primary aldosteronism. Hypertens Res. 2006; 29(11):883-9.

19. Sawka AM, Young WF, Thompson GB, Grant CS, Farley DR, Leibson C, et al. Primary aldosteronism: factors associated with normalization of blood pressure after surgery. Ann Intern Med. 2001;135(4):258-61. 
20. Milsom SR, Espiner EA, Nicholls MG, Gwynne J, Perry EG. The blood pressure response to unilateral adrenalectomy in primary aldosteronism. Q J Med. 1986;61(236):1141-51.

21. Celen O, O'Brien MJ, Melby JC, Beazley RM. Factors influencing outcome of surgery for primary aldosteronism. Arch Surg. 1996;131(6):646-50.

22. Wu VC, Chueh SC, Chang HW, Lin LY, Liu KL, Lin YH, et al. Association of kidney function with residual hypertension after treatment of aldosterone-producing adenoma. Am J Kidney Dis. 2009;54(4):665-73.

23. Steichen O. Hypertension cure rate after adrenalectomy for unilateral primary aldosteronism. J Surg Oncol. 2013;107(5):561.

24. Espiner EA, Ross DG, Yandle TG, Richards AM, Hunt PJ. Predicting surgically remedial primary aldosteronism: role of adrenal scanning, posture testing, and adrenal vein sampling. J Clin Endocrinol Metab. 2003;88(8):3637-44.

25. Zarnegar R, Young WF Jr, Lee J, Sweet MP, Kebebew E, Farley $\mathrm{DR}$, et al. The aldosteronoma resolution score: predicting complete resolution of hypertension after adrenalectomy for aldosteronoma. Ann Surg. 2008;247(3):511-8.

26. Bernini G, Moretti A, Argenio G, Salvetti A. Primary aldosteronism in normokalemic patients with adrenal incidentalomas. Eur J Endocrinol. 2002;146(4):523-9.

27. Kono T, Ikeda F, Oseko F, Imura H, Tanimura H. Normotensive primary aldosteronism: report of a case. J Clin Endocrinol Metab. 1981;52(5):1009-13.

28. Kaplan NM. The current epidemic of primary aldosteronism: causes and consequences. J Hypertens. 2004;22(5):863-9.

29. Blumenfeld JD, Sealey JE, Schlussel Y, Vaughan ED Jr, Sos TA, Atlas SA, et al. Diagnosis and treatment of primary hyperaldosteronism. Ann Intern Med. 1994;121(11):877-85.

30. Schwartz GL, Turner ST. Screening for primary aldosteronism in essential hypertension: diagnostic accuracy of the ratio of plasma aldosterone concentration to plasma renin activity. Clin Chem. 2005;51(2):386-94.

31. Weinberger MH, Fineberg NS. The diagnosis of primary aldosteronism and separation of two major subtypes. Arch Intern Med. 1993;153(18):2125-9.

32. White ML, Gauger PG, Doherty GM, Cho KJ, Thompson NW, Hammer GD, et al. The role of radiologic studies in the evaluation and management of primary hyperaldosteronism. Surgery. 2008;144(6):926-33 (discussion 33).

33. Young WF, Stanson AW, Thompson GB, Grant CS, Farley DR, van Heerden JA. Role for adrenal venous sampling in primary aldosteronism. Surgery. 2004;136(6):1227-35.

34. Mathur A, Kemp CD, Dutta U, Baid S, Ayala A, Chang RE, et al. Consequences of adrenal venous sampling in primary hyperaldosteronism and predictors of unilateral adrenal disease. J Am Coll Surg. 2010;211(3):384-90.

35. Nwariaku FE, Miller BS, Auchus R, Holt S, Watumull L, Dolmatch B, et al. Primary hyperaldosteronism: effect of adrenal vein sampling on surgical outcome. Arch Surg. 2006;141(5): 497-502 discussion-3.

36. Mulatero P, Bertello C, Rossato D, Mengozzi G, Milan A, Garrone $\mathrm{C}$, et al. Roles of clinical criteria, computed tomography scan, and adrenal vein sampling in differential diagnosis of primary aldosteronism subtypes. J Clin Endocrinol Metab. 2008; 93(4):1366-71.

37. • Kempers MJ, Lenders JW, van Outheusden L, van der Wilt GJ, Schultze Kool LJ, Hermus AR, et al. Systematic review: diagnostic procedures to differentiate unilateral from bilateral adrenal abnormality in primary aldosteronism. Ann Intern Med. 2009; 151(5):329-37. Systematic review of adults with primary hyperaldosteronism undergoing cross-sectional diagnostic imaging with computed tomography or magnetic resonance imaging as well as adrenal venous sampling to determine concordance of lateralization. The authors identified 38 studies of 950 patients with a $37.8 \%$ rate of discordant lateralization from CT or MRI based on imaging alone.

38. Magill SB, Raff H, Shaker JL, Brickner RC, Knechtges TE, Kehoe ME, et al. Comparison of adrenal vein sampling and computed tomography in the differentiation of primary aldosteronism. J Clin Endocrinol Metab. 2001;86(3):1066-71.

39. Sarlon-Bartoli G, Michel N, Taieb D, Mancini J, Gonthier C, Silhol F, et al. Adrenal venous sampling is crucial before an adrenalectomy whatever the adrenal-nodule size on computed tomography. J Hypertens. 2011;29(6):1196-202.

40. Melby JC, Spark RF, Dale SL, Egdahl RH, Kahn PC. Diagnosis and localization of aldosterone-producing adenomas by adrenalvein catheterization. N Engl J Med. 1967;277(20):1050-6.

41. Geisinger MA, Zelch MG, Bravo EL, Risius BF, O'Donovan PB, Borkowski GP. Primary hyperaldosteronism: comparison of CT, adrenal venography, and venous sampling. AJR Am J Roentgenol. 1983;141(2):299-302.

42. Zarnegar R, Bloom AI, Lee J, Kerlan RK Jr, Wilson MW, Laberge JM, et al. Is adrenal venous sampling necessary in all patients with hyperaldosteronism before adrenalectomy? J Vasc Interv Radiol. 2008;19(1):66-71.

43. Kupers EM, Amar L, Raynaud A, Plouin PF, Steichen O. A clinical prediction score to diagnose unilateral primary aldosteronism. J Clin Endocrinol Metab. 2012;97(10):3530-7.

44. Carr CE, Cope C, Cohen DL, Fraker DL, Trerotola SO. Comparison of sequential versus simultaneous methods of adrenal venous sampling. J Vasc Interv Radiol. 2004;15(11):1245-50.

45. Seccia TM, Miotto D, De Toni R, Pitter G, Mantero F, Pessina $\mathrm{AC}$, et al. Adrenocorticotropic hormone stimulation during adrenal vein sampling for identifying surgically curable subtypes of primary aldosteronism: comparison of 3 different protocols. Hypertension. 2009;53(5):761-6.

46. - Rossi GP, Barisa M, Allolio B, Auchus RJ, Amar L, Cohen D, et al. The Adrenal Vein Sampling International Study (AVIS) for identifying the major subtypes of primary aldosteronism. J Clin Endocrinol Metab. 2012;97(5):1606-14. An observational, retrospective, multi-center international study to determine practice patterns and complications of AVS. Among the 2,604 patients from 20 centers, AVS was utilized in $77 \%$ of patients with a rate of adrenal venous rupture of $0.61 \%$.

47. Young WF, Stanson AW. What are the keys to successful adrenal venous sampling (AVS) in patients with primary aldosteronism? Clin Endocrinol (Oxf). 2009;70(1):14-7.

48. Ceral J, Solar M, Krajina A, Ballon M, Suba P, Cap J. Adrenal venous sampling in primary aldosteronism: a low dilution of adrenal venous blood is crucial for a correct interpretation of the results. Eur J Endocrinol. 2010;162(1):101-7.

49. Dekkers T, Arntz MJ, van der Wilt GJ, Schultze Kool LJ, Sweep FC, Hermus AR, et al. Single versus duplicate blood samples in ACTH stimulated adrenal vein sampling. Clin Chim Acta. 2013;423:15-7.

50. Rossi GP, Pitter G, Bernante P, Motta R, Feltrin G, Miotto D. Adrenal vein sampling for primary aldosteronism: the assessment of selectivity and lateralization of aldosterone excess baseline and after adrenocorticotropic hormone (ACTH) stimulation. J Hypertens. 2008;26(5):989-97.

51. Daunt N. Adrenal vein sampling: how to make it quick, easy, and successful. Radiographics. 2005;25(Suppl 1):S143-58.

52. Rossi GP, Sacchetto A, Chiesura-Corona M, De Toni R, Gallina M, Feltrin GP, et al. Identification of the etiology of primary aldosteronism with adrenal vein sampling in patients with equivocal computed tomography and magnetic resonance findings: results in 104 consecutive cases. J Clin Endocrinol Metab. 2001;86(3):1083-90.

53. Rossi GP, Ganzaroli C, Miotto D, De Toni R, Palumbo G, Feltrin GP, et al. Dynamic testing with high-dose adrenocorticotrophic 
hormone does not improve lateralization of aldosterone oversecretion in primary aldosteronism patients. J Hypertens. 2006; 24(2):371-9.

54. Sacks BA, Brook OR, Brennan IM. Adrenal venous sampling: promises and pitfalls. Curr Opin Endocrinol Diabetes Obes. 2013;20(3):180-5.

55. Tanemoto M, Suzuki T, Abe M, Abe T, Ito S. Physiologic variance of corticotropin affects diagnosis in adrenal vein sampling. Eur J Endocrinol. 2009;160(3):459-63.

56. Elliott P, Holmes DT. Adrenal vein sampling: substantial need for technical improvement at regional referral centres. Clin Biochem. 2013;46(15):1399-404.

57. - Monticone S, Satoh F, Giacchetti G, Viola A, Morimoto R, Kudo M, et al. Effect of adrenocorticotropic hormone stimulation during adrenal vein sampling in primary aldosteronism. Hypertension. 2012;59(4):840-6. Study of ACTH stimulated AVS in 76 patients with non-stimulated, infusion, and bolus ACTH with findings of improved lateralization rates for both ACTH-stimulated conditions over non-stimulated AVS.

58. Bouhanick B, Delchier MC, Fauvel J, Rousseau H, Amar J, Chamontin B. Is it useful to repeat an adrenal venous sampling in patients with primary hyperaldosteronism? Ann Cardiol Angeiol (Paris). 2013; doi:10.1016/j.ancard.2013.04.003.

59. • Webb R, Mathur A, Chang R, Baid S, Nilubol N, Libutti SK, et al. What is the best criterion for the interpretation of adrenal vein sample results in patients with primary hyperaldosteronism? Ann Surg Oncol. 2012;19(6):1881-6. Retrospective review of 108 patients with primary hyperaldosteronism at a single center to determine the most accurate lateralization criteria for AVS results. The authors found that an SI of greater than five in ACTH-stimulated AVS with an LI of greater than four was the most accurate in identifying and correctly determining laterality of disease with a true positive rate of $88 \%$.

60. Levinson PD, Zadik Z, Hamilton BP, Mersey JH, White RI, Kowarski AA. Adrenal vein epinephrine levels: a useful aid in venous sampling for primary aldosteronism. Ann Intern Med. 1982;97(5):690-3.

61. Baba Y, Hayashi S, Nakajo M. Are catecholamine-derived indexes in adrenal venous sampling useful for judging selectivity and laterality in patients with primary aldosteronism? Endocrine. 2013;43(3):611-7.

62. Baba Y, Nakajo M, Hayashi S. Adrenal venous catecholamine concentrations in patients with adrenal masses other than pheochromocytoma. Endocrine. 2013;43(1):219-24.

63. Oh EM, Lee KE, Yoon K, Kim SY, Kim HC, Youn YK. Value of adrenal venous sampling for lesion localization in primary aldosteronism. World J Surg. 2012;36(10):2522-7.

64. Harvey A, Kline G, Pasieka JL. Adrenal venous sampling in primary hyperaldosteronism: comparison of radiographic with biochemical success and the clinical decision-making with "less than ideal" testing. Surgery. 2006;140(6):847-53 discussion 53-5.

65. Reardon MA, Angle JF, Abi-Jaoudeh N, Bruns DE, Haverstick $\mathrm{DM}$, Matsumoto $\mathrm{AH}$, et al. Intraprocedural cortisol levels in the evaluation of proper catheter placement in adrenal venous sampling. J Vasc Interv Radiol. 2011;22(11):1575-80.
66. Betz MJ, Degenhart C, Fischer E, Pallauf A, Brand V, Linsenmaier U, et al. Adrenal vein sampling using rapid cortisol assays in primary aldosteronism is useful in centers with low success rates. Eur J Endocrinol. 2011;165(2):301-6.

67. Auchus RJ, Michaelis C, Wians FH Jr, Dolmatch BL, Josephs SC, Trimmer CK, et al. Rapid cortisol assays improve the success rate of adrenal vein sampling for primary aldosteronism. Ann Surg. 2009;249(2):318-21.

68. Mengozzi G, Rossato D, Bertello C, Garrone C, Milan A, Pagni $\mathrm{R}$, et al. Rapid cortisol assay during adrenal vein sampling in patients with primary aldosteronism. Clin Chem. 2007;53(11): $1968-71$.

69. Georgiades CS, Hong K, Geschwind JF, Liddell R, Syed L, Kharlip J, et al. Adjunctive use of C-arm CT may eliminate technical failure in adrenal vein sampling. J Vasc Interv Radiol. 2007;18(9):1102-5.

70. Plank C, Wolf F, Langenberger H, Loewe C, Schoder M, Lammer J. Adrenal venous sampling using Dyna-CT: a practical guide. Eur J Radiol. 2012;81(9):2304-7.

71. Higashide $\mathrm{T}$, Funabashi $\mathrm{N}$, Tanaka $\mathrm{T}$, Inoue $\mathrm{K}$, Kazama $\mathrm{T}$, Motoori K, et al. Detection of adrenal veins on selective retrograde CT adrenal venography in comparison with digital subtraction angiography in subjects with established diagnosis of one-sided adrenal aldosterone-producing tumor confirmed by adrenal vein sampling, histopathology and clinical course. Int J Cardiol. 2013;168(4):3254-8.

72. Harvey A, Pasieka JL, Kline G, So B. Modification of the protocol for selective adrenal venous sampling results in both a significant increase in the accuracy and necessity of the procedure in the management of patients with primary hyperaldosteronism. Surgery. 2012;152(4):643-9 discussion 9-51.

73. Solar M, Ceral J, Krajina A, Ballon M, Malirova E, Brodak M, et al. Adrenal venous sampling: where is the aldosterone disappearing to? Cardiovasc Intervent Radiol. 2010;33(4):760-5.

74. Toniato A, Bernante P, Rossi GP, Pelizzo MR. The role of adrenal venous sampling in the surgical management of primary aldosteronism. World J Surg. 2006;30(4):624-7.

75. Schwab CW 2nd, Vingan H, Fabrizio MD. Usefulness of adrenal vein sampling in the evaluation of aldosteronism. J Endourol. 2008;22(6):1247-50.

76. Minami I, Yoshimoto T, Hirono Y, Izumiyama H, Doi M, Hirata Y. Diagnostic accuracy of adrenal venous sampling in comparison with other parameters in primary aldosteronism. Endocr J. 2008;55(5):839-46.

77. Satoh F, Abe T, Tanemoto M, Nakamura M, Abe M, Uruno A, et al. Localization of aldosterone-producing adrenocortical adenomas: significance of adrenal venous sampling. Hypertens Res. 2007;30(11):1083-95.

78. Salem V, Hopkins TG, El-Gayar H, Zac-Varghese S, Goldstone AP, Todd JF, et al. Adrenal venous sampling as a diagnostic procedure for primary hyperaldosteronism: experience from a tertiary referral centre. Hormones (Athens). 2012;11(2):151-9.

79. Nakamura Y, Satoh F, Morimoto R, Kudo M, Takase K, GomezSanchez CE, et al. 18-oxocortisol measurement in adrenal vein sampling as a biomarker for subclassifying primary aldosteronism. J Clin Endocrinol Metab. 2011;96(8):E1272-8. 